\title{
Juveniles Justice
}

\section{Phillip D. Clingan}

\author{
Pierce College, Criminal Justice Department, USA \\ *Corresponding author details: Dr. Phillip D. Clingan; dr.phillipclingan@gmail.com
}

\begin{abstract}
The research paper addresses the problem of mastering the literature to analyze theories, interventions, strategies, and treatment programs for juvenile delinquency. The solution to this problem will help juveniles, families, and the community works together to prevent juvenile offending and make amends to the community and victims. This researcher identifies evidence-based intervention programs, theoretical causes, and multisystem therapies through secondary resources to solve this problem. These resources examine the use of evidence-based intervention and early education programs to reduce the risk of juvenile delinquency. Combined, the resources determine that an evidence-based intervention is designed specifically for juvenile offenders. The juveniles range from committing part-one index crimes to falling in and out of home services. The writing assignment describes and justifies the research problem. The literature approach compares and summarizes sources used to address theories that explain the causes of delinquency and intervention designed to stop misconduct. The research paper identifies the relationship between age and crime theory, non-parentchild attachment, and objects that lead to juvenile delinquency. The research findings illustrate how this researcher presented criminology literature to support the research problem.
\end{abstract}

Keywords: juvenile delinquency; juvenile justice; juvenile decisions; juvenile actions; index crime

\section{INTRODUCTION}

Many theories attempt to explain why juveniles commit crimes. Why youths fail to attach to parents and approaches to identify interventions to deter criminal offending (Piquero, Farrington, Welsh, Tremblay, \& Jennings, 2009). Juvenile misbehaviors and criminal offending theoretically start in early childhood. Specifically, these behaviors surface and become urges, and disruptive behavior occurs into adolescence and early adulthood (Piquero et al., 2009). Early prevention is one of the main goals to prevent behavior that disrupts the family from the youth and the community. When a parent and child can work together in early preventive training, the parents teach children how to solve problems and the effects of misguided decisions (Piquero et al., 2009).

Even though research illustrates that failed attachment between child-parent relationships causes low academic results and a high risk for juvenile delinquency, early prevention can deter criminally offending. More critical, establishing evidence-based interventions that specifically target the criminal activity of the juvenile and the personality of the individual and family can lead to positive outcomes. Incorporating evidence-based interventions programs such as multidimensional treatment foster care programs, violence prevention, functional family therapy, and targeted delinquency programs will help deter future juvenile offending.

The research paper tries to examine criminology literature relevant to the research problem. The research paper includes reviewing and discussing criminology literature related to the research topic in two sections. The first section consists of a discussion of prominent literature, which analyzes theoretical approaches. The second section of the research paper includes a case study of juvenile delinquents. One of the juvenile's experiences is expressed in the course text and the video called When Kids Get Life. The research paper identifies relevant and existing information that will justify the research while evaluating the literature within the past five years of research information. The following literature summarizes the sources used as supportive evidence to investigate the potential relationship between theories. The literature examines a detailed analysis of:

(1) Theoretical Causes of Juvenile Delinquency

(2) Strategies and Interventions to Stop Juvenile Delinquency

(3) Pro's and Con's to Strategies and Interventions

Criminology seeks to understand and rationalize criminal behavior related to juvenile delinquency (Bartollas \& Miller, 2011). For example, the Rational Choice Theory assumes the juvenile voluntarily violates the law and uses free will. Regarding the classical school of criminology, the rational choice theory is the doctrine and is a deterrence that focuses irrationality of the offender. But, more important, juvenile delinquency does not rationalize behavior before committing a criminal act (Bartollas \& Miller, 2011).

\section{DISCUSSION}

Despite the attention juvenile delinquents receive from committing illegal acts, one factor remains present and continues to develop theories of juvenile offending: age (Sweeten, Piquero, \& Steinberg, 2013). Theories justify a multitude of psychological, biological, and sociological factors that explain the behaviors of the juvenile delinquent, especially between the ages of adolescence into young adulthood. Research shows that age is the number one direct effect on crime (Sweeten et al., 2013).

\section{Theoretical Causes of Juvenile Delinquency}

One continued theory or perhaps a practicing mindset of the juvenile justice system is that when juveniles commit a crime, they deserve punishment rather than treatment (Bartollas \& Miller, 2011). This theory explains that the juvenile offender commits the act voluntarily and purposefully, supporting the rational choice theory. 
And the young offender weighs the pros and the cons based on the most significant potential gains when committing the act (Bartollas \& Miller, 2011)

Current research shows a strong correlation between age and crime in adolescence (Sweeten et al., 2013). Criminal activity and antisocial behavior are present in the early teen years, peaks at 17, and rapidly declines after 17 into early adulthood (Sweeten et al., 2013). One opinion among criminologists is psychological or social logical variables can explain no relationship regarding juvenile delinquency. The view is that age is a direct factor in crime as it is expected that adolescents commit crimes before the age of 17 than as young adults (Sweeten et al., 2013).

The rational choice theory no longer expresses the view where every action is reasonable yet is moved to a more constrained role regarding the rational thought of the juvenile offender (Bartollas \& Miller, 2011). The theory no longer assumes that the delinquent commits a clear, planned, criminal act, well-informed decision, or even calculates the choices leading to the criminal act. Argumentatively, the rational choice theory focuses through a different lens other than rationality and focuses upon the individual's free will. The theory of delinquent behavior is that rationality may not be present in most crimes committed by juvenile delinquents (Bartollas \& Miller, 2011).

Regarding juvenile delinquency, age and crime theory research is the leading theory to support criminally offending in juveniles. There is a strong correlation between two ideas supporting juvenile offending: attachment and delinquency (Hoeve Stams, \& Van der Put, 2012). Attachment is closely associated with juvenile delinquency, as research suggests that wretched attachment to parents increases the risk of delinquency behavior. The question is, could there be a link between attachment and delinquency? According to modern research (Hoeve et al., 2012), two theories connect the theoretical causes of juvenile delinquency, the attachment theory and the social control theory.

The attachment theory is founded within the philosophy of criminological conceptualization and that the attachments of the juvenile bond are based on conventional norms of the community or society (Hoeve et al., 2012). Delinquency occurs when the ties are low and quantifiable within the family construct. Therefore, juveniles with secure attachments to their parents are less likely to commit criminal acts in her more likely to meet parent expectations socially resisting delinquent impulses (Hoeve et al., 2012). And the theory solidifies the argument that a juvenile's behavior is predictable and conventional and is the byproduct of a secure attachment between child and parent. More importantly, delinquent behavior occurs when a weak attachment between child and parent (Hoeve et al., 2012).

The attachment theory focused on the impact of the childparent attachment relationship, which, when broken, can lead to juvenile delinquency; the control theory focuses more on abnormal development (Hoeve et al., 2012). The control theory explains how juveniles commit criminal acts based on environmental factors such as social control. The youth lacks affection between the child and the parents, which could positively influence the child's predictive behavior. The behavior is psychologically through the parent's presence (Hoeve et al., 2012).

Therefore, social theory expresses the necessity for affection bonds, yet the attachment theory requires no affection bond (Hoeve et al., 2012). Despite the comparisons between social control theory and the attachment theory, one can hypothesize that disruption of attachment between the juvenile and parent can lead to high-risk behavior (Hoeve et al., 2012).

\section{Strategies and Interventions to Stop Juvenile Delinquency}

Evidence shows four correctional models' widely used philosophies illustrate interventions and strategies used to prevent juvenile delinquency. The models include the treatment model, the justice model, the crime control model, and the balance and restorative justice model (Bartollas \& Miller, 2011). The treatment model is based on a philosophical approach operated within the juvenile court. The court steps in and assumes legally the parent role over children or juveniles neglected and considered custodial care and discipline over the youth. The court takes the role seriously and approaches the child to determine historical difficulties and justifications that led to the child or juvenile making misbehavior decisions. And the juvenile court assumes a social clinic position meeting all medical, education, and social needs of the child. The treatment model is based on the philosophical approach of parens patriae (Bartollas \& Miller, 2011).

The function of the treatment model is to rehabilitate the juvenile by providing mental, social needs, and physical needs before being processed into the juvenile system (Bartollas \& Miller, 2011). In addition, for the juvenile offender, the police officers may recommend programs to assist the parents and the youth in understanding better one another in identifying specific problems that may lead to a criminal offense. Some programs within the treatment model include probation officers, drug, and alcohol programs, tutoring, afterschool programs, anger management, and other treatment modalities specific to the youth (Bartollas \& Miller, 2011).

One of the primary objectives of health treatment and strategies for juvenile delinquency is the prevention of behaviors that lead to offending (Piquero, Farrington, Welsh, Tremblay, \& Jennings, 2009). Early parents and juvenile training are one of the most effective interventions and treatment strategies that help reduce problematic behaviors. Research indicates that initial prevention training for the parent and the juvenile reduces crime and delinquency in later ages of adolescence and into young adulthood (Piquero et al., 2009). And early treatment prevention targets high-risk families and can be very beneficial when receiving early services to deter early life behavioral problems.

The Justice model incorporates the due process philosophy to protect juvenile offenders' protection in safeguards through the due process of the juvenile justice system (Bartollas \& Miller, 2011). The Justice model redesigned the intent following the 1970s due to inadequacies in the juvenile justice law, practiced law, and juvenile policies. As a result, reformers turned to concept models of justice and just desserts models for both juvenile and adult offenders (Bartollas \& Miller, 2011). The primary intent of the justice model is to ensure that proportionality is ever-present and that punishment matches the crime committed. And correctional education programming must be based solely on the offender's compliance, attitudes, and personal history. The watchword of the justice model is to ensure that the system is reliable, reasonable, constitutional, and humane (Bartollas \& Miller, 2011).

The proponent and advocacy of the justice model are to ensure current changes and fairness is ever-present in the juvenile justice system. For example, the juvenile courts have enormous amounts of discretion, which allow them to divert young offenders to voluntary services instead of the formal justice system (Bartollas \& Miller, 2011). 
Tailor indeterminate sentencing procedures of the juvenile justice system and incorporate a fixed sentence timeline for juvenile offenders. Ensure that status offenders' offenses become decriminalized (Bartollas \& Miller, 2011).

Make public and training schools safer. Require that the juvenile offender make restitution and perform community service. Incorporating sanctions towards juvenile offenders shows the fairness of the justice system. More importantly, the programs teach youthful offenders to take responsibility for their actions and make amends for the harm inflicted upon the community (Bartollas \& Miller, 2011).

The crime control model emphasizes that punishment is a natural process for juvenile offenders (Bartollas \& Miller, 2011). Though the crime control model philosophy has existed since the 18th century, the model has gained notoriety in the 1970s due to the rise of juvenile crimes. One idea that supports the crime control model is that punishment is always beneficial because it reinforces our society's view of education and morals (Bartollas \& Miller, 2011). In addition, when a juvenile offender receives a sentence, defenders are also taught not to commit future crimes as incarcerated in juvenile facilities or adult facilities should deter crime (Bartollas \& Miller, 2011).

More importantly, the crime control model supporters view that the juvenile justice system has abandoned punishment altogether for rehabilitating the juvenile (Bartollas \& Miller, 2011). Perhaps punishment is advocated when used to incarcerate the offender. But the same supporters of the crime control model also view juvenile misbehaviors as abnormal and unlawful, which only punishment can correct (Bartollas \& Miller, 2011). The crime control model as deterrence of the juvenile justice system or punishing juvenile offenders brings certainty, efficiency, and speed through the juvenile justice system (Bartollas \& Miller, 2011).

The priority of the crime control model towards the prevention of juvenile delinquency is to protect property in the life of the innocent (Bartollas \& Miller, 2011).

The supporters of the crime control model also view that police involvement is swift and may isolate the juvenile offender, especially juveniles that have committed part one crime. The crime control model and the justice model work together when transferring juveniles to adult court (Bartollas \& Miller, 2011). Explicitly, when sentencing laws may specify that serious crimes committed may extend confinement for the juvenile. The crime control model is viewed as making a paradigm shift from treatment and rehabilitation to punishments (Bartollas \& Miller, 2011).

The last intervention strategy for juvenile delinquency is the balanced and restorative justice model (Bartollas \& Miller, 2011). The model is rapidly expanding around the world and throughout the United States. The system ensures that resources are allocated to ensure accountability to the victims of crimes, educate the offender, and ensure committee safety (Bartollas \& Miller, 2011). The three goals of the balance to restorative justice model are competency, community protection, and accountability (Bartollas \& Miller, 2011).

Accountability is having the juvenile offender accept responsibility for the criminal activity and misbehaviors, mainly when they cause harm to innocent victims and must restitute to the victims (Bartollas \& Miller, 2011). One caveat to accountability is an assumption that having the offender takes responsibility will meet the community's outcomes of justice. Competency refers to the juvenile offender receiving education programs, emotional therapy, social and vocational training. More importantly, other modalities ensure the offender can return to the community as a law-abiding citizen (Bartollas \& Miller, 2011).

Community protection means educating leaders of the citizenry to resolve conflict, prevent crime, and feel safe. More important, the juvenile justice system has taught the young offender to be responsible citizens back into the community (Bartollas \& Miller, 2011). The balance in the restorative justice model primarily works through the juvenile justice system and finds alternative processing for youth within the community. Once the juvenile offender has been identified as committing a criminal act, a probation officer, volunteer representative, a police officer, or designated guardian will initiate restorative justice protocols (Bartollas \& Miller, 2011).

The community's incorporation makes the balanced and restorative justice model one of the primary models used to treat juvenile delinquency. For example, the victim, the offender, the offender's family, law enforcement, and community volunteers all come together to discuss the problems and future of the youth (Bartollas \& Miller, 2011). The intervention identifies the co-participants within the balanced and restorative justice model.

For example, the victim will actively explain the harm the crime caused them explaining the obligation placed back on the juvenile offender (Bartollas \& Miller, 2011). The community comes together to assist the victim, takes responsibility for holding the juvenile offender responsible for their criminal misbehavior, and puts a plan to amend. The offender also takes an active participation role in competency development in repairing the community and the victim (Bartollas \& Miller, 2011). The most effective interventions are incorporating early prevention programs for young and older adolescents using multisystemic therapy, parent training, community programs, and restorative justice programs (Piquero et al., 2009).

\section{Pro's and Con's to Strategies and Interventions}

One significant con consistently applied to the interventions and strategies to prevent juvenile delinquency are explicitly identifying the causal mechanisms that reduce crime and delinquency, yet consistent (Piquero et al., 2009). Though early identification is a positive aspect, the negative is the difficulty in consistently identifying causal mechanisms to decrease misbehaviors. Therefore, the Pro identifies followup and follow-through treatment programs regarding antisocial behavior, delinquency, and how crime can affect one's life course (Piquero et al., 2009).

The crime control model expresses a contrary view where the model supports long-term confinement in a juvenile facility rather than short-term incarcerations for the juvenile offender. Supporters of the crime control model would empathize that punishment is a deterrence that should be the primary focus over rehabilitation (Bartollas \& Miller, 2011). The positive aspect of the treatment model is juvenile offenders can receive therapy rather than being placed in an institution. The Justice model presents a positive outlook that ensures due process and procedural safeguards for the juvenile offender. Negatively, the Justice model views the juvenile offender's punishment as proportionate to the gravity of the crimes committed (Bartollas \& Miller, 2011).

The Pro of the balanced and restorative justice model is that juvenile offenders have free will and exercise that decision when committing criminal offenses (Bartollas \& Miller, 2011). The advantage of the model is a proponent of punishment over the justice model and the crime control model and dramatically supports the due process of the juvenile offender. 
Much like the justice model, the balanced and restorative justice model places the consequences of juvenile misbehavior and encourages young offenders to be open to treatment (Bartollas \& Miller, 2011).

No doubt that each model approaches treatment and strategies to prevent juvenile delinquency can be argued. Juvenile justice organizations and personnel to include support agencies continue to choose from each model, which they prefer day-to-day (Bartollas \& Miller, 2011).

The supporter's approach to treating and preventing juvenile delinquency greatly influences which model is chosen to work with the juvenile offenders. In a student's opinion, picking and choosing multiple models designed to treat juvenile delinquency can cause conflicting approaches to helping young juvenile offenders. Contingent if one supports the crime control model, the balanced and restorative justice model, or the treatment model. The model chosen depends on the different courses of actions taken and confuses within the juvenile justice system (Bartollas \& Miller, 201).

\section{When Kids Get Life}

The film looks at the lives of five juveniles in Colorado sentenced to existence without the chance for further appeal as adolescents (Public Broadcasting Station [PBS] 2007). In the late 1980s and 1990s, Colorado changed its laws to support discipline over rehabilitation. The justice system uprooted the likelihood of parole sentences and made it simpler for the senior prosecutor's office to treat adolescents as grown-ups (PBS, 2007). The film takes a glance at the results in the lives of these five people. The research paper focuses on Erik Jensen, the crimes committed, juvenile behavior, family and school influence, environmental factors, and theories. More importantly, this researcher is picking Erik Jensen because Erik was from a loving family, and Erik remains regarded as a healthy child and without misbehaviors. Erik would support Nathan, decide where the brain is not developed enough, and cost Erik his freedom for life (PBS, 2007).

\section{Family Influence Juvenile Behavior}

Erik Jensen is from an upper-class suburban community outside of Denver, Colorado. Erik's closest friend Nathan Ybanez claims Eric is an ordinary kid (PBS, 2007). Erik and Nathan met at school and created a band together. Curt and Pat Jensen, parents of Erik, would attend each band's concerts to support Eric and extend that support to Nathan, Erik's friend. Erik would speak with Nathan's mother, Julie, and she would ask if Nathan could stay at Erik's house on several occasions, so Nathan would not come home (PBS, 2007). Nathan is from a troubled home where mental abuse and physical violence occur. Erik is from a very emotionally and physically loved home, and Erik's parents supported the choices Erik made and the friends Erik would choose (PBS, 2007). Erik and the parents established a child-parent relationship that exhibits trust.

Theoretically, the most crucial factor influencing a teenager's behavior is the family (Marcu \& Filimon, 2013). Family provides emotional, cultural support, materials, education, care, love, and other modalities for the teenager to be fulfilled. The love and emotional support a family can give directly to the teenager's mental and physical development (Marcu \& Filimon, 2013). Curt and Pat's love exuded to Erik is why Nathan claims Erik was a healthy child. This researcher asserts the theoretical description above illustrates the life Nathan did not have and was not living.

\section{How School Influence Subsequent Behaviors}

Erik Jensen was a good student in school from a loving family, and Erik received anything he wanted, a room in the basement, food, shelter, and always felt worthy (PBS, 2007). Erik did not display antisocial or aggressive behavior while in the school environment. Nathan showed antisocial behavior due to fighting internal emotions stemming from conflict within the home environment (PBS, 2007). Erik would invite friends from school over to the house and conduct band practice in the basement. Erik can live his life as he chooses about these parents. The freedom permitted Erik to express love and social behavior with the parents, which led to understanding and accepting the child-parent relationship (Marcu \& Filimon, 2013).

Children through adolescent age learn a great deal more than just math or history in the school environment. They were explicitly witnessing violence, early exposure to imitations of violence, acceptance of aggressive behavior, and using aggressive behavior to achieve individual goals and a school environment (Mrug \& Windle, 2009). Recent research provides a view of problematic behaviors and antisocial behaviors that stem from the school environment. Studies show that aggressive behaviors and victimization during middle childhood development become early predictors of adolescents' externalizing problems, aggression, and delinquency (Mrug \& Windle, 2009).

Recent research illustrates that school environments directly affect adolescent behavior in three areas: cognitive, emotional, and behavioral (Hirschfield \& Gasper, 2011). First, there is a strong relationship between the misconduct in bidirectional, which may lead to common causes among peers and family relationships as early indicators of high-risk behavior. The common emotional reaction is a predictor of decreased school activity and a high proponent of delinquency. Finally, criminology illustrates a strong correlation between misconduct and poor academic performance (Hirschfield \& Gasper, 2011). For example, an adolescent from a low physical and emotional home life and exudes poor academic performance will most likely lead to delinquent behavior. Conversely, a juvenile from a loving and supportive home will perform academically emit low cognitive behaviors to juvenile offending (Hirschfield \& Gasper, 2011).

\section{Environmental Factors}

Witnessing community violence greatly influenced the adolescent mentality of social normative beliefs. Adolescents' thoughts on violence and aggressive behaviors lead to decision-making and problem-solving. However, witnessing physical violence, aggressive behaviors, and victimization can lead to juvenile aggression and delinquency (Mrug \& Windle, 2009). Erik Jensen is from a predominantly white community. Demographics such as ethnicity can capture how social and cultural processes influence juveniles to disengage from family and exude juvenile offending behaviors (Hirschfield \& Gasper, 2011).

Erik's age is the prominent role that, in a student's opinion, compromised the plausibility of helping Nathan cover up the murder of Nathan's mother, Julie. More critical, plausibility directly influences the friendship bond between Erik and Nathan and affects the relationship among other peers and family dynamics (Hirschfield \& Gasper, 2011). The family dynamics, Erik's ethnicity, and social processing of Erik Jensen is the answer to why Erik participated in helping his friend Nathan cover up a heinous crime. Love and support are the most influential environmental factors supporting moral decision-making to help a friend (Hirschfield \& Gasper, 2011). 
This researcher contains no measurable evidence to capture why a friend would help another friend cover up a murder. Perhaps a radical premise is that delinquency is caused by solid family dynamics and the influence of the school bond, friendship, and significance of peers.

\section{Theory Supports Juvenile Decision (Opinion)}

In this researcher's opinion, no functional criminological theory supports why a juvenile helps a friend to cover up a murder. Erik Jensen asserts they did not think that he was confused and didn't understand the situation in which his friend Nathan presented (PBS, 2007). Erik Jensen's race in a loving and supportive family liked his friend Nathan and desperately wanted to help him. The only theory to support the juvenile decides that your pressure in goodness inside Erik Jensen based on family dynamics, moral virtue, and family values is why Erik helped his friend Nathan. In this researcher's opinion, no criminological theory should be founded to express and support the criminal mind theory where one person justifies killing another. But what one friend will do for another will continue to surprise the society and seek to explain how one person lives their lives and ever equate to approve criminality.

\section{Theory Explains Juvenile Actions}

The age and crime theory appear across all demographic groups, cultures, and communities in the United States (Sweeten et al., 2013). The age crime theory claims the juvenile may have self-control, a trait stable after childhood, and explains why crime varies at all ages. And the distribution of age and crime cannot be accounted for as all environmental variables would be considered. Research shows regarding the age and crime theory that crime changes dramatically before and after late ages of adolescents (Sweeten et al., 2013).

The rational choice theory capitalizes on the free will of the juvenile when performing criminal acts (Bartollas \& Miller, 2007). Erik Jensen's behavior as an explanation by his friend Nathan and character witnessed by his family shows no potential to criminal offending (PBS, 2007). Theoretically, Erik Jensen is explained using the age and crime theory and the rational choice theory. Erik, at 16, describes the covariance utilized to justify the relationship between age and crime and free will to cover up the crime (Henggeler \& Schoenwald, 2011).

\section{Possible Preventive Programs}

Reducing criminal behavior in young adolescence is one of the number one goals for society. Implementing community, county, state, and local governments programs such as evidence-based interventions through sustainability can deter juvenile offenders (Henggeler \& Schoenwald, 2011). Evidence-based interventions include applications such as the juvenile justice system, probation, surveillance, residential placements, group homes, incarceration, boot camp, shock incarceration, and other modalities. In addition, evidence-based interventions address high-risk factors that will decrease deviant behavior and help improve the childparent relationship (Henggeler \& Schoenwald, 2011).

In 2008, law enforcement agencies in the United States arrested over 2,111,200 juveniles, with $25 \%$ of the arrest about violent part one-index crimes (Henggeler \& Schoenwald, 2011). Of the juveniles arrested and eligible for juvenile justice processing, $66 \%$ remained in juvenile court, and $10 \%$ or transferred directly to adult court (Henggeler \& Schoenwald, 2011). In this researcher's opinion, the juveniles, family, and community must come together to identify what works and what programs do not work. Some of the costliest programs related to the juvenile justice system are residential placement programs such as wilderness programs, residential treatment centers, detention centers, group homes, and correctional institutions (Henggeler \& Schoenwald, 2011).

Effective intervention programs targeting delinquency, violence prevention, and drug prevention our functional family therapy, multi-systemic therapy in multidimensional treatment foster care programs (Henggeler \& Schoenwald, 2011). The preventive programs mentioned abasing years of experimentation where evidence is dignified to deter juvenile delinquency by successfully replicating sustainability outcomes for at least one year. The research conducted within one year leads to successful intervention programs for juvenile offenders (Henggeler \& Schoenwald, 2011).

Functional family therapy is a community-based treatment program where the participants include status offenders in youth that show antisocial behavior (Henggeler \& Schoenwald, 2011). The program decreases antisocial behavior in young people, primarily juveniles from dysfunctional families. The plan would integrate cognitivebehavioral interventions, anger management, assertiveness training, and other treatment protocols and modalities that focus on the relationship between the child and the parent. Programs designed to emphasize educating and motivating family members that directly affect efforts between the family and the juvenile for behavioral changes (Henggeler \& Schoenwald, 2011).

The multiple systemic therapies are a community and family-based treatment program that focuses on severe clinical problems related to the juvenile offender (Henggeler \& Schoenwald, 2011). The program treats young sexual offenders, substance abuse, and violent young offenders who show high-risk behaviors outside the home. Programs are designed to decrease reoffending by placing the juvenile in a residential program to receive evidence-based psychological treatment (Henggeler \& Schoenwald, 2011). The program is comprehensive in addressing factors of the juvenile, specifically family, cognitive biases, and prosocial activities. The goal is to improve family functioning, decrease the deviant relationship between peers, and decrease Association to show and produce favorable outcomes for the juvenile offender. The juvenile and the family members work together in residential therapy to meet the youth and the family (Henggeler \& Schoenwald, 2011).

The multidimensional treatment foster care programs; it's a community-based program alternative to state detention facilities (Henggeler \& Schoenwald, 2011). Specifically, the program is designed where intensive home and in-home services have failed. The goal is for the juvenile to learn through punishment and overt reward that impacts the context of learning. In addition, the program uses cognitivebehavioral approaches to help the minor understand problem-solving skills and identify the triggers that cause misbehaviors (Henggeler \& Schoenwald, 2011).

The design framework emphasizes counseling parents to understand the role of supervision and monitoring while engaging the juvenile in peer activities while successfully disengaging the juvenile from deviant peers. The parents receive training to help promote positive school performance and involve other treatment elements. The practice emphasizes mechanisms that change behavior, incredibly antisocial behavior without medication (Henggeler \& Schoenwald, 2011).

\section{SUMMARY}

Overall, the research paper identified the theoretical causes of juvenile delinquency. Primarily, there is a strong correlation between age and crime in adolescence. The rational choice theory claims the juvenile acts without planning, establishes a well-formed decision, or calculates how poor choices lead to criminal offending. 
Correctly, the juvenile operates under the umbrella of the rational choice theory claiming that the offender uses free will to commit a criminal act. And the attachment theory identifies juvenile offending due to poor child-parent attachment relationships, and control theory explains how delinquency is based on environmental factors. Poor decisions can be found in home life, emotional attachments to friends and family, and mental development regarding decision-making that leads to criminal offending. Last, an evidence-based intervention program is needed to educate the family and the juvenile while reducing high-risk behaviors that lead to a poor decision and returning the youth to family and community.

\section{ANALYSIS}

There are four intervention models used to stop juvenile delinquency. The models include the justice model, the crime control model, the treatment model, and the balance and restorative justice model. (Bartollas \& Miller, 2011). When compared against the other models, the crime control model is the deterrence of the juvenile justice system. Notably, punishing juvenile offenders brings certainty, efficiency, and speed through the juvenile justice system (Bartollas \& Miller, 2011). Finally, the most widely used model is the balanced and restorative justice model. The model, when used properly, brings the community together to assist the victim and holds the juvenile offender responsible. More importantly, it puts a plan for the offender to amend (Bartollas \& Miller, 2011).

Two pros and cons to strategies and intervention include the crime control model and the justice model. The crime control model is a con and claims long-term confinement best serves the community can empathize with punishment over deterrence. On the other hand, the justice model takes a positive approach and ensures due process and procedural safeguards for the juvenile (Bartollas \& Miller, 2011).

Based on this researcher's opinion, Erik Jensen supported his friend Nathan to cover up the murder of his mother Julie because Erik is from a loving and balanced home. More importantly, Erik was a good student from the exclusive white community, upper-middle-class suburbia outside Denver, Colorado. Due to the strong relationship between Erik and the parents, Erik is compelled to support his friend Nathan in a time of trouble. Unfortunately, this researcher has no measurable data to help other than the operational theories of how family influences juvenile behavior.

Law enforcement arrested over 2,111,200 juveniles in 2008 (Henggeler \& Schoenwald, 2011). Of the juveniles arrested, $25 \%$ were part-one index crimes, $10 \%$ of the youths were transferred to adult court, while $66 \%$ remain in juvenile court (Henggeler \& Schoenwald, 2011). Effective early intervention programs are desperately needed on a national scale to specifically target juvenile delinquency, drug prevention, functional family therapy, and violence prevention programs. These programs can support a multi-systemic treatment that is evidence-based and shows significant results to deter juvenile delinquency (Henggeler \& Schoenwald, 2011).

\section{NEED FOR FUTURE RESEARCH}

Overall, the research paper mastered the literature used to determine a detailed analysis of theories, interventions, strategies, and treatment programs for juvenile delinquency. Detail analysis causes intervention programs and policies for juvenile delinquency. Correctly, literature critiques scholarly sources to analyze theories and possible approaches study Erik Jensen, a juvenile delinquent. More research remains needed to determine if evidenced-based treatment programs and criminology theories explain why juveniles are offended criminally.

\section{REFERENCES}

[1] Bartollas, C., \& Miller, S. J. (2011). Juvenile justice in America (6th ed.). Upper Saddle River, NJ: Prentice-Hall.

[2] Henggeler, S., \& Schoenwald, S. (2011). Evidencebased interventions for juvenile offenders and juvenile justice policies that support them. Society for Research in Child Development, 25(1), 2-28. Retrieved from https://www.rockies.edu

[3] Hirschfield, P., \& Gasper, J. (2011). The relationship between school engagement and delinquency in late childhood and early adolescence. Youth Adolescence, 40[V1], 3-22. http://dx.doi.org/10.1007/s10964010-9579-5

[4] Hoeve, M., J., G. J., Stams, M., \& Van der Put, C. E. (2012, January 27). A meta-analysis of attachment to parents and delinquency. J Abnormal Child Psychology, 40, 771-785.

http://dx.doi.org/10.1007/s10802-011-9608-1

[5] Marcu, R., \& Filimon, L. (2013, July). Causal model of behavior problems perception by the teenager's families. Internatio[V2] $\mathrm{n}$ Journal of Education and Psychology in the Community, 3(2), 22-37. Retrieved from http://www.rockies.edu/proquest

[6] Mrug, S., \& Windle, M. (2009). Bidirectional influences of violence exposure and adjustment in early adolescence: externalizing behaviors and school connectedness. Abnormal Child Psychology, 37, 611-623. http://dx.doi.org/10.1007/s10802009-9304-6

[7] Piquero, A., Farrington, D., Welsh, B., Tremblay, R., \& Jennings, W. (2009). Effects of early family/parent training programs on antisocial behavior and delinquency. J Exp Criminol, 5, 83-120. http://dx.doi.org/10.1007/s1129-009-9072-x

[8] Public Broadcasting Station. (2007, May). When Kids Get Life [Video file]. Retrieved from http://www.pbs.org/wgbh/pages/frontline/whenk idsgetlife/view/

[9] Sweeten, G., Piquero, A. R., \& Steinberg, L. (2013). Age and explanation of crime revisited. J Youth Adolescence, 42, 921-938. doi.org/10.1007/s10964013-9926-4 